Marquette University

e-Publications@Marquette

School of Dentistry Faculty Research and

Publications

Dentistry, School of

$9-1998$

\title{
Lateral cephalometric analysis of asymptomatic volunteers and symptomatic patients with and without bilateral temporomandibular joint disk displacement
}

\author{
Jose A. Bosio \\ Marquette University, jose.bosio@marquette.edu \\ James G. Burch \\ Ohio State University - Main Campus \\ Ross H. Tallents \\ Dale B. Wade \\ Ohio State University - Main Campus \\ Frank M. Beck
}

Follow this and additional works at: https://epublications.marquette.edu/dentistry_fac

Part of the Dentistry Commons

\section{Recommended Citation}

Bosio, Jose A.; Burch, James G.; Tallents, Ross H.; Wade, Dale B.; and Beck, Frank M., "Lateral cephalometric analysis of asymptomatic volunteers and symptomatic patients with and without bilateral temporomandibular joint disk displacement" (1998). School of Dentistry Faculty Research and Publications. 23.

https://epublications.marquette.edu/dentistry_fac/23 
Marquette University

\section{e-Publications@Marquette}

\section{School of Dentistry Faculty Research and Publications/School of Dentistry}

This paper is NOT THE PUBLISHED VERSION; but the author's final, peer-reviewed manuscript. The published version may be accessed by following the link in th citation below.

American Journal of Orthodontics and Dentofacial Orthopedics, Vol. 114, No. 3 (September, 1998): 248-255. DOI. This article is (C) Elsevier and permission has been granted for this version to appear in e-Publications@Marquette. Elsevier does not grant permission for this article to be further copied/distributed or hosted elsewhere without the express permission from Elsevier.

\section{Contents}

Abstract.

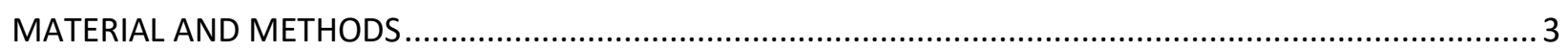

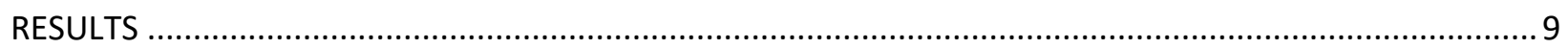

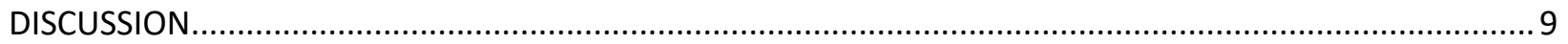

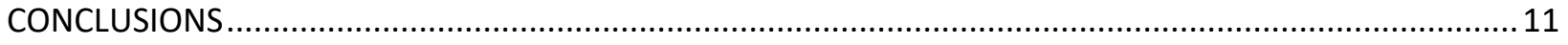

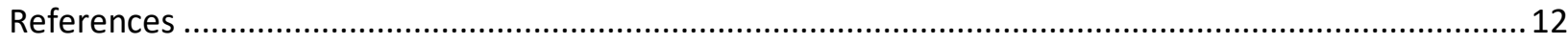

\section{Lateral cephalometric analysis of asymptomatic volunteers and symptomatic patients with and without bilateral temporomandibular joint disk displacement}


José A. Bósio

Private Practice, Brazil

James G. Burch

Departments of Orthodontics and Periodontology, Ohio State University, $\mathrm{OH}$

Ross H. Tallents

Department of Prosthodontics and Orthodontics and Temporomandibular Joint Disorders, Eastman Dental Center, Rochester, NY

Dale B. Wade

Department of Orthodontics, Ohio State University, $\mathrm{OH}$

Frank M. Beck

Department of Health Services Research, Ohio State University, $\mathrm{OH}$

\section{Abstract}

Few studies of dentofacial and orthodontic structural relationships relative to temporomandibular joint (TMJ) dysfunction have been reported. We undertook this investigation to determine any correlation of orthodontic and dentofacial characteristics with TMJ bilateral disc displacement. The population of patients was selected from a TMJ clinic where a control group of asymptomatic volunteers had been previously established and standardized. Differences in skeletal structural features were determined among three study groups: (1) asymptomatic volunteers with no TMJ disk displacement, (2) symptomatic patients with no TMJ disc displacement, and (3) symptomatic patients with bilateral TMJ disk displacement. Thirty-two asymptomatic volunteers without disk displacement ( 25 female, 7 male) were compared with the same number each of symptomatic patients without TMJ disk displacement and symptomatic patients with bilateral TMJ disk displacement. All subjects had undergone a standardized clinical examination, bilateral TMJ magnetic resonance imaging, and lateral cephalometric radiographic analysis. The groups were matched according to sex, TMJ status, age, and Angle classification of malocclusion. Seventeen lateral cephalometric radiographic cranial base, maxillomandibular, and vertical dimension variables were evaluated and compared among the study groups. The mean angle of SNB, or the intersection of the sella-nasion plane and the nasion-point B line (indicating mandibular retrognathism relative to cranial base), of the symptomatic patients-withdisplacement group was significantly smaller than that in the asymptomatic volunteers and symptomatic patients without bilateral disk displacement $(p, 0.05)$. Female subjects showed smaller linear measurements of mandibular length, lower facial height, and total anterior facial height than male subjects in all three groups $(p, 0.05)$. The mean angle of ANB, or the intersection of the nasion-point $A$ and nasion- point $B$ planes (indicating retrognathism of mandible relative to maxilla), was significantly greater in female than in male subjects, in all groups $(p, 0.05)$. Symptomatic patients with bilateral disk displacement had a retropositioned mandible, indicated by a smaller mean SNB angle compared with that in asymptomatic volunteers and symptomatic patients with no disk displacement on either side. Lateral cephalometric radiographic assessment may improve predictability of TMJ disk displacement in orthodontic patients but is not diagnostic; nor does the assessment explain any cause-and-effect relationship. 
One fourth to one half the U.S. population has signs or symptoms of temporomandibular joint (TMJ) or masticatory-muscle disorders, and as many as $5 \%$ may require treatment. ${ }^{1}, \underline{2}, \underline{3}$ In the past, diagnoses of these disorders were made on the basis of therapeutic success with occlusal splint treatment. If symptoms were relieved, the patient was considered to have an occlusal dysfunction, and therapy was continued accordingly. ${ }^{4}$

Clinical examination questionnaires ${ }^{1}, \underline{5}, \underline{6}$ and plain radiographic films $\stackrel{7}{\underline{7}} \underline{\underline{9}}, \underline{9}$ of the TMJ have been obtained in the past as a common practice to diagnose temporomandibular disorders (TMDs). Substantial gains in differential diagnosis have been made in the past 15 years with the introduction of imaging modalities such as arthrography, $\underline{\underline{10}}, \underline{11}$ computed tomography, $\underline{\underline{12}}, \underline{13}$ and magnetic resonance imaging (MRI). $\underline{14}, \underline{15}, \underline{16}$ Now, more definitive and accurate diagnosis of internal derangement can be made. $\underline{17}$

In few studies have skeletal features, mandibular form, or differences in TMD patients from an orthodontic perspective been reported. Nickerson and Moystad $\stackrel{18}{ }$ reported condylar shortening and failure to achieve full development of the condyle in young patients with disk displacement without reduction. In comparing subjects with TMJ structural or functional problems with normal subjects, Stringert and Worms $\stackrel{19}{ }$ reported a significant trend toward hyperdivergent subjects. Tallents and coworkers $\underline{\underline{20}}$ found mandibular plane angle in subjects in a dysfunction population to be greater than that in asymptomatic subjects. A large study of adolescents presenting for orthognathic surgery with internal derangement revealed an increased likelihood of retrognathic mandibles, small and deformed condyles, shortened ramal height, and prominent antegonial notching. ${ }^{21}$ Link and Nickerson $\underline{22}$ studied 39 patients undergoing orthognathic surgery and found a high degree of association between a mandibular deficiency and internal derangement. They suggested that internal derangement has a role in mandibular deficiency. Schellhas, Piper, and Omlie $\underline{\underline{23}}$ observed 100 patients with external mandibular deformity and concluded that TMJ degeneration is the main cause of both acquired facial skeleton remodeling and unstable occlusion in patients with intact dentition and without previous mandible fracture. Brand et al..$\underline{24}$ compared 23 asymptomatic subjects with 24 symptomatic patients. All subjects underwent clinical examination and bilateral MRI. Cephalometric analysis showed no distinct relationship between structural features of the face and presence or absence of TMJ internal derangement. $\underline{24}$

The aim of this retrospective investigation was to determine the relationship of skeletal structural features, which are traditionally assessed in the orthodontic specialty practice, with occurrence of TMJ internal derangement. If a statistically significant correlation could be found, the orthodontist might then better understand the frequency of internal derangement in patients with given skeletal forms. We also sought to give direction to future retrospective and prospective investigations of clinically diagnostic and cause-and-effect relationships of TMDs in various orthodontic populations. If correlations are found to be strongly significant, predictions and the diagnostic abilities of the clinical orthodontist will be enhanced.

\section{MATERIAL AND METHODS}

This retrospective study was designed to evaluate differences in skeletal structural characteristics, determined on cephalometric analysis, between asymptomatic volunteers and symptomatic patients. Selection criteria were more definitive than those of previous studies. $\underline{19}$, $\underline{24}$ Male and female subjects with bilateral disk displacement were included. Unilateral disk-displacement subjects were excluded. 
The groups were matched for sex, TMJ status (presence or absence of bilateral disk displacement), age, and Angle classification of malocclusion.

Two hundred eighty-three subjects were examined at the Eastman Dental Center TMJ Clinic, Rochester, N.Y. Eighty-two were established as asymptomatic volunteers ( 40 male, 42 female), and 201 were symptomatic patients ( 28 male, 137 female). Each subject signed a consent form permitting investigation and underwent standardized TMD clinical examination, lateral cephalometric radiography, and bilateral MRI. $\underline{24}, \underline{25}, \underline{26}, \underline{27} \underline{28}$ We examined the following clinical parameters: facial symmetry; range of protrusive, horizontal, and vertical mandibular movement (in millimeters); opening patterns; type and stage of opening and closing joint sounds detected on auscultation; Angle classification of dental malocclusion; canine or group lateral excursive movements; overbite; overjet; presence of crossbite; abnormal wear; bruxism; balancing side contacts; missing teeth (not including third molars); tilted or extruded teeth; periodontal status; and pain sensation on muscle palpation. ${ }^{29}$ The asymptomatic subjects were screened for the absence of the following signs and symptoms: localized pain in the TMJ or ear, pain on mandibular movement, headaches aggravated by jaw movement, presence of joint sounds (on the basis of history and physical examination), limited mandibular range of vertical opening ( $\leq 40 \mathrm{~mm}$ ) and horizontal ( $\leq 5 \mathrm{~mm}$ ) movements, deviation on mandibular opening, history of locking, history of trauma, and history of TMD treatment. $\underline{30}$

Symptomatic patients were selected consecutively from patients referred to the TMJ clinic for diagnosis and treatment of TMDs. Subjects were included if they presented with the signs and symptoms mentioned above and consented to participate in the study. Subjects with missing molar or incisor teeth and those with unilateral TMJ disk displacement were excluded.

MRI examinations were performed with a 1.5T imager (Signa, General Electric). A body coil was used to transmit the radio-frequency pulses, and a custom $6 \times 8-\mathrm{cm}$ surface coil served as the receiver. On the basis of data from an axial localizer, sagittal and coronal $3 \mathrm{~mm}$ sections were obtained through the joints of the patients. $\underline{29}$ The images were obtained at angles perpendicular and parallel to the horizontal long axes of the condyles. The scanning sequences for the patient samples included an axial localizer \{repetition time $[T R]=400 \mathrm{msec}$, echo time $(T E)=11 \mathrm{msec}$ or $12 \mathrm{msec}$, one NEX (number of excitation), field of view $(F O V)=18 \mathrm{~cm}$, and matrix $=128 \times 256$ or $256 \times 192\}$, sagittal closed- and open-mouth views, and a coronal closed-mouth view. For the pulse sequence of the sagittal closed-mouth view, TR was 2,000 msec, TE 19 and $80 \mathrm{msec}$, NEX 0.5, FOV $10 \mathrm{~cm}$, and matrix $192 \times 256$. For the pulse sequence of the sagittal open-mouth view, TR was $1500 \mathrm{msec}$, TE 19 and $80 \mathrm{msec}$, NEX 0.75 , FOV $10 \mathrm{~cm}$, and matrix $128 \times 256$. The scanning times for each plane of scanning were 8 minutes, 56 seconds. $\underline{29}$ The images were classified according to the method of Tasaki et al. $\underline{30}$

After appropriate preliminary exclusions from the original population, 191 subjects were selected for this study. They were divided into three groups: (1) asymptomatic volunteers without TMJ disk displacement on either side (29 male, 25 females), (2) symptomatic patients without TMJ disk displacement on either side ( 7 male, 28 female), and (3) symptomatic patients with bilateral TMJ disk displacement (11 male, 91 female). To maximize the power of the statistical analysis, sex subgroups were matched to the smallest number of male and female subjects in any study group, 7 male and 25 female, then matched according to age and Angle classification of malocclusion. (Table I). 
Table I Distribution of Angle classification of malocclusion among the groups

\begin{tabular}{|l|l|l|l|l|l|}
\hline & $\begin{array}{l}\text { Angle } \\
\text { classification* }\end{array}$ & & & \\
\hline Group & I & II/1 & II/2 & $\begin{array}{l}\text { II/1 } \\
\text { subdivision }\end{array}$ & III \\
\hline $\begin{array}{l}\text { Symptomatic without } \\
\text { internal derangement }\end{array}$ & $16(30)$ & $8(36)$ & $1(14)$ & $0(0.00)$ & $7(50.00)$ \\
\hline $\begin{array}{l}\text { Symptomatic with internal } \\
\text { derangement }\end{array}$ & $17(33)$ & $8(36)$ & $3(43)$ & $1(100.00)$ & $3(21)$ \\
\hline $\begin{array}{l}\text { Asymptomatic without } \\
\text { internal derangement }\end{array}$ & $19(37)$ & $6(28)$ & $3(43)$ & $0(0.00)$ & $4(29)$ \\
\hline $\begin{array}{l}\text { * Data expressed as no. (\%). } \\
\text { (3) }\end{array}$ & & & & \\
\hline
\end{tabular}

Lateral cephalometric radiographs were made for all subjects with the teeth in centric occlusion position and the Frankfort horizontal plane parallel to the floor. Cephalometric radiographs were traced and digitized. Ten cephalometric head plates were retraced and redigitized 3 months later and the reliability of analysis determined. The same 10 head-plate tracings were manually assessed and compared by means of digital analysis to detect reproducibility of the two methods. Cephalometric landmarks used in the study are shown in Fig. 1.

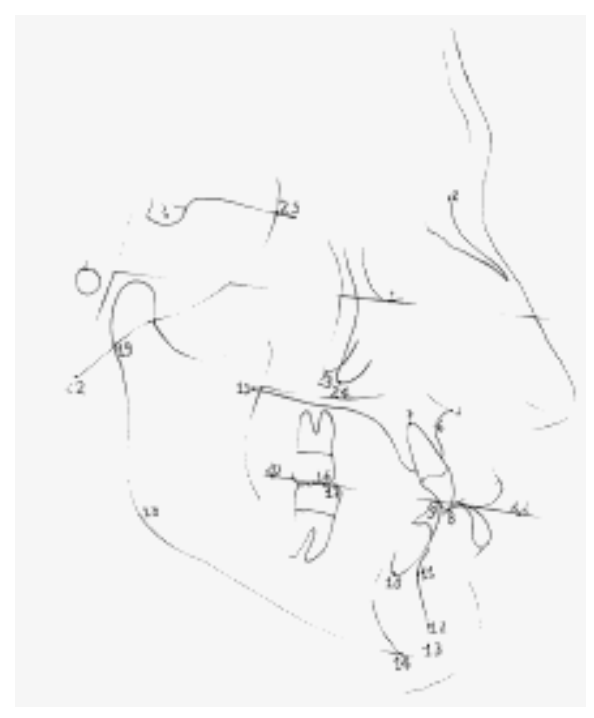

Fig. 1 Cephalometric points: 1, sella; 2, nasion; 3, porion; 4, orbitale; 5, anterior nasal spine ; 6, point A; 7,maxillary incisor apex; 8, incisor tip U1; 9, incisor tip L1; 10, mandibular incisor apex; 11, point B; 12, pogonion; 13, gnathion; 14, menton; 15 , posterior nasal spine; 16 , mesial buccal cusp 
U6; 17, mesial buccal cusp L6; 18, gonion; 19, articulare; 20, occlusal plane (posterior point); 21 , occlusal plane (anterior point); 22, basion; 23, key ridge apex left; 24, key ridge apex right; 25, sphenoethmoidal junction.

Planes are defined in Table II.

Table II Planes used in the study

1. Sella-nasion: the plane from sella to nasion

2. Sella-basion: the plane from sella to basion

3. Basion-nasion: the plane from basion to nasion

4. Frankfort horizontal: the plane from porion to orbitale

5. Facial plane: the line from nasion to pogonion

6. Palatal plane: the plane from anterior nasal spine to posterior nasal spine

7. Nasion-point A: the line joining nasion to point $A$

8. Nasion-point $B$ : the line joining nasion to point $B$

9. Point $A-$ pogonion: the line joining point $A$ to pogonion

10. $Y$-axis: the line joining sella to gnathion

11. Mandibular plane: plane from menton and tangent to the lower border of the mandible

12. Articulare-gonion: plane from articulare to gonion

Linear, angular, and proportional measurements are described and abbreviations explained in Table III. Specific angular, linear, and proportional measurements are subgrouped with regard to to cranial base and maxillary, mandibular, intermaxillary, and vertical measurements in Table IV.

Table III Angular and linear dimensions used in the study

Angular dimensions

Basion-Sella-Nasion angle (BSN): the intersection of the Ba-S and the S-Na planes

Sella-Nasion to FH (SNFH): the intersection of the Sella-Nasion and FH planes

Facial Angle (FacAn): the intersection of the $\mathrm{FH}$ and the facial planes

Lande's angle: the intersection of the $\mathrm{FH}$ plane and the $\mathrm{Na}$-point $\mathrm{A}$ line

SNA: the intersection of the sella-nasion plane and the Nasion-A Point line

SNB: the intersection of the Sella-Nasion plane and the Nasion-B Point line

ANB: the intersection of the Nasion-A Point and the Nasion-B Point planes

Angle of Convexity (Convx): the intersection of the Nasion-A Point line and the point A-pogonion plane

Mandibular plane angle (ManPI): the intersection of the $\mathrm{FH}$ and the mandibular planes

Y-axis: the intersection of the $\mathrm{FH}$ and the sella-gnathion planes 
Gonial angle (GonAn): the intersection of the articulare-gonion plane and the mandibular plane Palatal plane-FH plane angle (PPFH): the intersection of the $\mathrm{FH}$ and the palatal planes

Palatal plane-mandibular plane angle (PPMP): the intersection of the palatal and mandibular planes Linear dimensions

Lower facial height (LFH): the distance (in $\mathrm{mm}$ ) from anterior nasal spine to menton

Total facial height (TFH): the combination (in $\mathrm{mm}$ ) of upper and lower facial height

Articulare-gonion length ( $\mathrm{ArGo}$ ): the distance (in $\mathrm{mm}$ ) from articulare to gonion

Proportional dimensions

Upper/total facial height (U/TFH\%): the ratio of upper to total facial height, expressed as a percentage

$F H$, Frankfort horizontal.

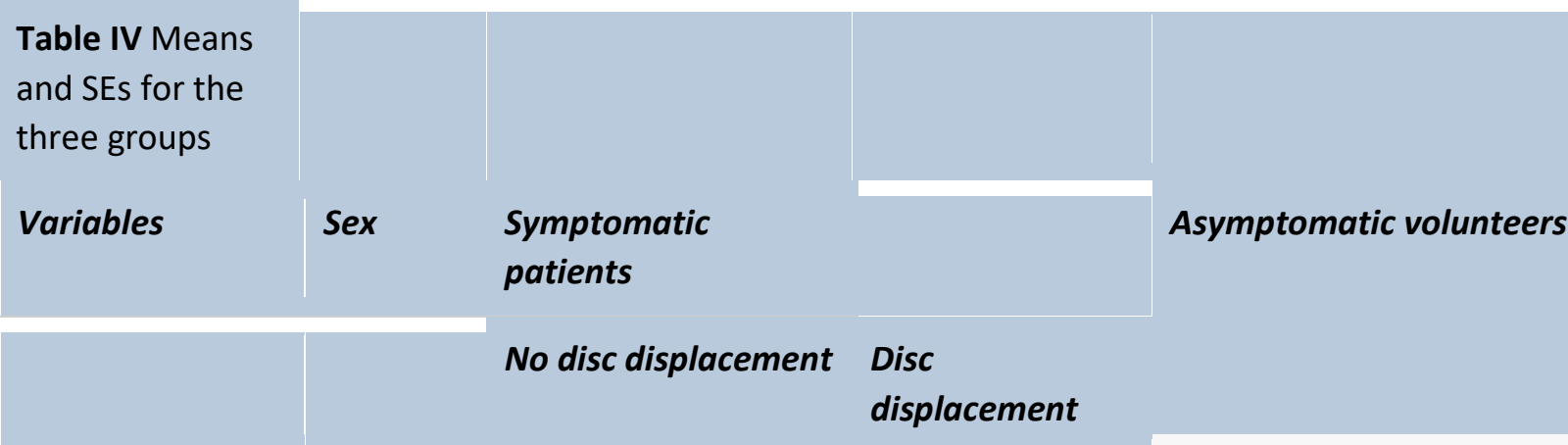

Cranial base

NS

Maxilla

NS

Mandible

FacAn NS

SNB

Male $\quad 81.0 \pm 2.0 *$

$77.7 \pm 0.8^{\dagger}$

$78.2 \pm 0.6^{*}$

Female $\quad 78.1 \pm 0.6^{*}$

$76.0 \pm 0.6+$

$79.7 \pm 0.8^{*}$ 


\begin{tabular}{|c|c|c|c|c|}
\hline ManPI & & & & \\
\hline Y-axis & NS & & & \\
\hline GonAn & & & & \\
\hline $\operatorname{ArGo}(m m)^{*}$ & Male & $54.7 \pm 2.7$ & $51.9 \pm 2.0$ & $51.7 \pm 2.3$ \\
\hline & Female & $47.6 \pm 0.9$ & $45.9 \pm 1.0$ & $47.3 \pm 1.1$ \\
\hline Intermaxillary & & & & \\
\hline ANB* & Male & $0.1 \pm 1.1$ & $2.3 \pm 0.9$ & $2.7 \pm 0.8$ \\
\hline & Female & $2.9 \pm 0.5$ & $3.8 \pm 0.5$ & $3.4 \pm 0.5$ \\
\hline
\end{tabular}

NS

PPMPa

Vertical

$\begin{array}{llll}\mathrm{LFH}(\mathrm{mm})^{*} \quad \text { Male } & 74.2 \pm 3.5 & 71.3 \pm 2.2 & 72.9 \pm 1.5\end{array}$

Female $\quad 66.4 \pm 1.0 \quad 65.9 \pm 1.2 \quad 65.5 \pm 1.0$

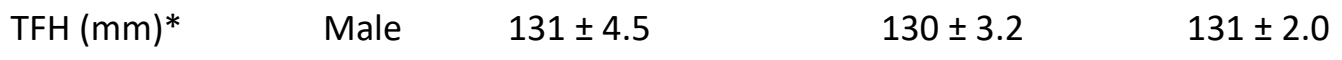

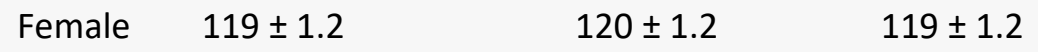

$\mathrm{U} / \mathrm{TFH} \% \quad$ NS

$*$ and + between-group differences; significant $(p<0.05)$. ¥Significant between-sex differences for all groups $(p<0.05)$.

See Table III for explanation of abbreviations.

Group differences for Angle classification were assessed with the use of Fisher's exact test (two-tailed). Means and SEs for age and cephalometric measurements were calculated and evaluated with factorial 
ANOVAs, with group and sex as the two independent variables. If indicated by a significant $F$ test result, post hoc testing was conducted with the Tukey procedure. We determined the reliability of measurements by calculating the intraclass correlation coefficient. All results were considered significant if the $p$ value was less than 0.05 .

\section{RESULTS}

No significant differences were found with regard to age or Angle classification between the control and the two symptomatic groups, proving matching criteria to be accurate (Table I). The mean age for all male groups ( 21 subjects) was $24.4 \pm 3.34$. The mean age for all female groups ( 75 subjects) was $28.6 \pm$ 1.3 .

The reliability of tracing, digitization, and analytical measurements had intraclass correlation coefficients greater than 0.92. Computer and manual measurements had an intraclass correlation coefficient greater than 0.980 .

No significant differences were seen in cranial base (BSN, SNFH) or maxillary (Lande's angle, SNA, PPFH) angle measurements in the study groups or between sexes (Table IV).

We found significant differences in two mandibular skeletal measurements (Table IV). Disk-displacement patients had a smaller mean SNB angle than those without disk displacement. The symptomatic patients with bilateral disk displacement (both male and female) had significantly smaller mean SNB angles than the symptomatic patients without disk displacement or the asymptomatic volunteers $(p<0.05)$. Fifty-six percent (14/25) of the female symptomatic patients with disk displacement demonstrated Angle Class I malocclusion. The subgroup had a mean SNB angle of $75.6^{\circ}$ (SE $=0.771, p<0.0001$ ). And $40 \%(10 / 25)$ of the female symptomatic patients with disk displacement had Angle Class II malocclusion. Their mean SNB angle was $76.3^{\circ}(\mathrm{SE}=1.18, p<0.05)$. Female subjects demonstrated shorter condylar height than male subjects. This significant difference was found only between sexes, not among the three study groups.

The intermaxillary mean ANB angles were significantly different between the sexes but not among the study groups. Female subjects demonstrated a mean ANB angle larger than that of male subjects (Table $\underline{\text { IV). }}$.

Vertical proportions showed no differences among study groups or between sexes (Table IV). However, vertical linear measurements revealed female subjects to be significantly smaller in lower face height and total face height than male subjects in all three study groups.

\section{DISCUSSION}

There were only 7 male symptomatic patients without disk displacement and 25 female asymptomatic volunteers without disk displacement. Subjects were matched for gender, TMJ status, age, and Angle classification of malocclusion. In the effort to match subgroup sizes, the sample size of all other subgroups were limited. The average age for the male population for all the three groups was 24.4 years; it was 28.6 years for the female groups. This age distribution was similar to that in other studies. $\underline{19}, \underline{21}, \underline{24}$ 
Arthrography and MRI have allowed differential diagnosis of disk displacement in TMD patients. Ronquillo et al. ${ }^{31}$ and Pullinger $\underline{32}$ have suggested that patients with disk displacement with reduction have a more posterior condyle position than do symptomatic normal subjects or patients with disk displacement without reduction ( $61 \%$ and $71 \%$, respectively). Ren, Isberg, and Westesson $\underline{33}$ showed that joints with disk displacement, especially those without reduction of the disk, have a more posterior condyle position than the asymptomatic normal joints. $\frac{33}{T}$ Therefore the knowledge of whether subjects have disk displacement when studying skeletal structural characteristics and differences between TMD patients and non-TMD subjects is important in clarifying the groups. The type of disk position may influence condylar position and, consequently, mandibular position. Furthermore, this could influence cephalometric skeletal structural and positional measures. However, one cannot assume that the displacement of the disk is the factor responsible for the posterior position of the condyle or the mandible; it could be the result of a posterior position of both structures. In the group of patients with symptomatic disk displacement, subjects with different types of disk displacement (with and without reduction) were combined into one group. The authors of future retrospective and prospective studies should consider this in patient selection and group subjects according to the type of disk displacement.

No differences were found for the cranial base or maxillary measurements among the three study groups (Table IV). Similar findings were reported previously. $\underline{20}, \underline{24}, \underline{34}, \underline{35}, \underline{36}$ Differences would not be expected because disk displacement in the TMJ does not affect cranial base and maxillary relationships.

The most significant finding in this study was that patients with bilateral disk displacement had a statistically significantly smaller mean SNB angle than the groups without disk displacement. The mean SNB angle determines the mandibular position in relation to the cranial base, according to standard measurements. If the mean SNB angle is smaller in subjects with disk displacement, one could speculate that the mandible was retropositioned as a result of anterior displacement of the articular disk. However, one cannot make that assumption because the positions of the condyle and mandible were not known before disk displacement occurred. Therefore disk displacement cannot be assumed to cause the posterior positioning of the condyle or mandible. The difference in mean SNB angle between the male subgroups was very small but, combined with the female subgroups, yielded a statistically significant difference. This difference may not be clinically significant and therefore not diagnostic.

The facial angle, which also shows the position of the mandible in relation to the cranial base, showed no differences among the three study groups. The facial angle is a reference plane based on anteroposterior position of the symphysis, not on the mandibular basal bone as is the SNB angle. The facial angle would be larger if the symphysis were prominent, whereas the SNB angle might remain normal. Therefore the SNB angle may be the more acceptable measurement of anteroposterior position of the mandible in TMD populations.

All linear mean values were significantly smaller for female subjects (Table IV). Female subjects were smaller on average than male subjects, as was reported by Brand et al. $\underline{\underline{24}}$ in a similar study and as reported years ago by Coben $\frac{37}{37}$ and by Wylie and Johnson $\underline{38}$ in cephalometric studies.

Stringert and Worms $\underline{19}$ found their experimental group (TMD patients) to have a larger mean ANB-angle value than their other patient group, which comprised individuals referred for orthognathic surgery. However, Brand and coworkers $\underline{24}$ do not confirm those findings. $\stackrel{24}{\underline{4}}$ Our study showed female subjects to have a significantly greater ANB angle than male subjects. This may be because the percentage of male 
subjects with Class III malocclusion (38\%) was much greater than the percentage of female subjects with this condition (8\%).

A commonly accepted mean SNB angle for normal subjects is $80^{\circ} . \underline{39}$ As found herein, patients who present with disk displacement have a more retropositioned mandible than has previously been reported to occur in symptomatic subjects with normal disk position. ${ }^{31}, 32,33$ In this study, $56 \%$ of the female symptomatic patients with disk displacement (14/25) presented with bilateral disk displacement and Angle class I malocclusion and had a mean SNB angle of $75.6^{\circ}(\mathrm{SE}=0.771)$. This value is significantly less $(p<0.0001)$ than the standard SNB angle for normal subjects. Forty percent of the female symptomatic patients with disk displacement (10/25) had Class II malocclusion. Their mean SNB angle was $76.3^{\circ}(\mathrm{SE}=1.18)$, significantly different $(p=0.0121)$ from the standard mean SNB angle for normal subjects. However, when the female Class II symptomatic patients with disk displacement were divided into Class II Division 1 and Class II Division 2, no statistically significant differences from the normal subjects were found. This finding might imply that predicting TMJ disk displacement from a lateral cephalometric radiograph could be possible if a patient presented with characteristic signs or symptoms of the TMJ, Angle Class I malocclusion, and SNB angle less than the mean calculated in this study $\left(75.6^{\circ}\right)$. That narrowly focused prediction may be possible, but it is not very practical and definitely not diagnostic.

The authors of future studies should control for transverse characteristics during patient selection. Also, differentiation of medial and lateral disk displacement is recommended; this could perhaps enhance the gathering of information of more diagnostic value. We further recommend that future studies be designed prospectively and with larger groups. Subjects should be chosen with signs or symptoms of TMD, SNB angle of $75.6^{\circ}$ or less, Angle Class I malocclusion, and matched age and sex, with joint status determined on the basis of MRI. If MRI showed a significantly higher prevalence of bilateral disk displacement, then the SNB angle of $75.6^{\circ}$ would be confirmed as a reliable diagnostic measurement. At this time one cannot consider an SNB angle less than $75.6^{\circ}$ suggestive of TMJ disk displacement. Furthermore, without the above selection criteria and scientific validation, lateral cephalometric analysis is not diagnostic of TMJ disk displacement. An observation concerning condyle or mandibular position at any point is simply an observation, and a staging of the pathologic process cannot be assumed. $\underline{40}$

The term "disk displacement" has been used in this article to describe the specific TMJ internal derangement features that have been described previously and to which the findings of this study were related. We refer the reader to two recent publications that recommend more terminology based on pathophysiology, accurate diagnosis, and appropriate treatment considerations. $\underline{41}, \underline{42}$

\section{CONCLUSIONS}

Ninety-six subjects ( 21 male, 75 female) were divided into three different groups with 32 subjects each: asymptomatic volunteers without internal derangement, symptomatic patients with internal derangement, and symptomatic patients with no internal derangement of either TMJ. All groups were matched by sex, joint status, age, and Angle classification of malocclusion. All subjects underwent standardized clinical examinations, bilateral MRI, and lateral cephalometric radiography. Statistical analysis of 17 cephalometric variables was conducted to investigate any differences among the three groups. 
Significant differences in SNB angular measurements among the three study groups were found. Significant differences were also found in ANB angle and all linear measurements between the sexes. No differences were found for proportional dimensions.

The following conclusions can be drawn from this study: (1) Symptomatic patients with bilateral TMJ disk displacement had a more retropositioned mandible, as indicated by a smaller mean SNB angle than that in asymptomatic volunteers and symptomatic patients with no disk displacement of either TMJ. (2) The mean SNB angle of $75.6^{\circ}$ or less was significantly related to disk displacement. However, this measurement must be further validated before being used as a diagnostic indicator of disk displacement. (3) ANB angle and all linear measurements are significantly different between male and female subjects but not different among the three study groups. (4) No significant differences were found in the cranial base, maxillary, vertical skeletal or intermaxillary relations among the three study groups.

\section{References}

1. Solberg, WK, Woo, MW, and Houston, JB. Prevalence of mandibular dysfunction in young adults. J Am Dent Assoc. 1979; 98: 25-34

2. Schiffman, EL, Fricton, JR, Haley, DP, and Burton, LS. The prevalence and treatment needs of subjects with temporomandibular disorders. J Am Dent Assoc. 1990; 210: 295-303

3. Nilner, M. Epidemiological studies in TMD patients. in: Current controversies in temporomandibular disorders.. Quintessence Publishing, Carol Stream, III; 1992: 53

4. Randolph, CS, Greene, CS, Moretti, R, Forbes, D, and Perry, HT. Conservative management of temporomandibular disorders: a posttreatment comparison between patients from a university clinic and from private practice. Am J Orthod Dentofac Orthop. 1990; 98: 77-82

5. Agerberg, G and Carlson, GE. Symptoms of dysfunctional disturbances of the masticatory system. II. Symptoms in relation to impaired mobility of the mandible as judged from investigation by questionnaire. Acta Odont Scand. 1973; 33: 337-347

6. Anderson, GC, Schiffman, EL, Schellhas, KP, and Fricton, JR. Clinical vs. arthrographic diagnosis of TMJ internal derangement. J Dent Res. 1989; 68: 826-829

7. Ricketts, RM. Abnormal function of the TMJ. Am J Orthod. 1955; 41: 435-441

8. Williamson, EH and Wilson, $\mathrm{CW}$. Use of submental-vertex analysis for producing quality temporomandibular joint laminagraphs. Am J Orthod. 1976; 70: 200-207

9. Gianelly, AA, Hughes, HM, Wohigemuth, and Gildea, G. Condylar position and extraction. Am J Orthod Dentofac Orthop. 1988; 93: 201-208

10. Farrar, WB and McCarty, WL Jr. Characteristics of the condylar path in internal derangements of the TMJ. J Prosth Dent. 1978; 39: 319-323

11. Wilkes, $\mathrm{CH}$. Arthrography of the temporomandibular joint in patients with the TMJ paindysfunction syndrome. Minn Med. 1978; 61: 645-652 
12. Manzione, JV, Katzberg, RW, Hammerschlag, SB, and Chiango, BF. Direct sagittal computed tomography of the temporomandibular joint. Am J Neuroradiol. 1982; 3: 677-679

13. Helms, CA, Richardson, ML, Vogler, JB, and Hoddick, WK. Computed tomography for diagnosing temporomandibular joint disk displacement. J Craniomand Pract. 1985; 3: 24-26

14. Helms, CA, Richardson, ML, Moon, KL, and Ware, $\mathrm{WH}$. Nuclear magnetic resonance imaging of the temporomandibular joint: preliminary observation. J Craniomandib Pract. 1984; 2: 219227

15. Katzberg, RW, Schenck, J, Roberts, D et al. Magnetic resonance imaging of the temporomandibular joint meniscus. Oral Surg Oral Med Oral Pathol. 1985; 59: 332-335

16. Katzberg, RW, Westesson, P-L, Tallents, RH et al. Temporomandibular joint: MR assessment of rotational and sideways disk displacements. Radiology. 1988; 169: 741-748

17. Paesani, D, Westesson, P-L, Hatala, MP, Tallents, RH, and Brooks, SL. Accuracy of clinical diagnosis for TMJ internal derangement and arthrosis. Oral Surg Oral Med Oral Pathol. 1992; 73: 360-363

18. Nickerson, JW and Møystad, A. Observation on individuals with radiographic bilateral condylar remodeling. J Craniomand Pract. 1982; 1: 21-37

19. Stringert, HG and Worms, FW. Variations in skeletal and dental patterns in patients with structural and functional alterations of the temporomandibular joint: a preliminary report. $A m$ J Orthod. 1986; 89: 285-297

20. Tallents, RH, Catania, J, Sommers, E et al. Cephalometric comparisons of patients with TMJ pain and dysfunction to normal standards. ([abstract])Farrar-Nørgaard Society meeting, Rochester, N.Y; August 1989

21. Nickerson, JW and Boering, G. Natural course of osteoarthrosis as it relates to internal derangement of the temporomandibular joint. Oral Maxillofac Surg North Am. 1989; 1: 27-45

22. Link, JJ and Nickerson, JW Jr. Temporomandibular joint internal derangements in an orthognathic surgery population. Int J Adult Orthod Orthog Surg. 1992; 7: 161-169

23. Schellhas, KP, Piper, MA, and Omlie, MR. Facial skeleton remodeling due to temporomandibular joint degeneration: an imaging study of $\mathbf{1 0 0}$ patients. Am J Neuroradiol. 1990; 11: 541-551

24. Brand, JW, Nielson, KJ, Tallents, RH, Nanda, RS, Currier, GF, and Owen, WL. Lateral cephalometric analysis of skeletal patterns in patients with and without internal derangement of the temporomandibular joint. Am J Orthod Dentofac Orthop. 1995; 107: 121-128

25. Roberts, CA, Tallents, RH, Katzberg, RW, Sanchez-Woodworth, RE, Espeland, MA, and Handelman, SL.Comparison of internal derangements of the TMJ with occlusal findings. Oral Surg Oral Med Oral Pathol. 1987; 63: 645-650 
26. Roberts, C, Katzberg, RW, Tallents, RH, Espeland, MA, and Handelman, SL. Correlation of clinical parameters to the arthrographic depiction of temporomandibular joint internal derangements. Oral Surg Oral Med Oral Pathol. 1988; 66: 32-36

27. Roberts, C, Katzberg, RW, Tallents, RH, Espeland, MA, and Handelman, SL. The clinical predictability of internal derangements of the temporomandibular joint. Oral Surg Oral Med Oral Pathol. 1991; 71: 412-414

28. Sanchez-Woodworth, RE, Tallents, RH, Katzberg, RW, and Guay, JA. Bilateral internal derangements of the temporomandibular joint: evaluation by magnetic resonance imaging. Oral Surg Oral Med Oral Pathol. 1988; 65: 281-285

29. Tasaki, MM. Magnetic resonance imaging and arthrographic assessment of temporomandibular joint disk displacements. Thesis. University of Umea, Umea, Sweden; 1993

30. Tasaki, MM, Westesson, P-L, Isberg, AM, Ren, Y-F, and Tallents, RH. Classification and prevalence of temporomandibular joint disk displacement in patients and symptom-free volunteers. Am J Orthod Dentofac Orthop. 1996; 109: 249-262

31. Ronquillo, HI, Guay, J, Tallents, RH, Katzberg, RW, and Murphy, W. Tomography analyses of mandibular condyle position as compared to arthrographic findings of the temporomandibular joint. J Craniomand Disord. 1988; 2: 59-64

32. Pullinger, AG. The significance of condyle position in normal and abnormal temporomandibular joint function. in: Perspectives in temporomandibular disorders.. Quintessence Publishing, Chicago; 1987: 89-103

33. Ren, Y-F, Isberg, A, and Westesson, P-L. Condyle position in the temporomandibular joint. Oral Surg Oral Med Oral Pathol Oral Radiol Endod. 1995; 80: 101-107

34. Bósio, JB, Tallents, RH, Dimadura, ALL, Murphy, W, and Proskin, H. Lateral cephalometric analysis of cranial base in a population with and without internal derangement of the TMJ. ([abstract])EDC Orthodontics Alumni Meeting, Rochester, N.Y; 1992

35. Subtelny, JD and Sakuda, M. Open-bite: diagnosis and treatment. Am J Orthod. 1964; 50: 337358

36. Moore, JW. Variation of the sella-nasion plane and its effect on (SN)A and (SN)B. J Oral Surg. 1976;34: 24-26

37. Coben, SE. The integration of facial skeletal variants: a serial cephalometric roentgenographic analysis of craniofacial form and growth. Am J Orthod. 1955; 41: 407-434

38. Wylie, $W$ and Johnson, E. Rapid evolution of facial dysplasia in the vertical plane. Angle Orthod. 1952; 22: 165-182

39. Riedel, RA. The relation of maxillary structures to cranium in malocclusion and in normal occlusion. Angle Orthod. 1952; 22: 142-145

40. Tallents, RH, Catania, J, and Sommers, E. Temporomandibular joint findings in pediatric population and young adults: a critical review. Angle Orthod. 1991; 61: 7-16 
41. Okeson, JP. Orofacial pain: guidelines for assessment, diagnosis, and management. in: Quintessence Publishing, Chicago; 1996: 113-118

42. Stohler, CS. Disk-displacement disorders. in: Temporomandibular joint and masticatory muscle disorders.. Mosby-Year Book, St. Louis; 1994: 271-297 